\title{
Characterizing the Areal Density and Desorption Kinetics of Physically Adsorbed Polymer in Polymer Nanocomposite Melts
}

\author{
SUPPLEMENTAL INFORMATION
}

Eric J. Bailey, Philip J. Griffin, Russell J. Composto, and Karen I. Winey*

Department of Materials Science and Engineering, University of Pennsylvania, Philadelphia, Pennsylvania 19104, United States

*Author to whom correspondence should be addressed. Electronic address: winey@seas.upenn.edu 


\section{$\underline{\text { I. Dispersion of } \mathrm{SiO}_{2} \text { NPs in P2VP }}$}
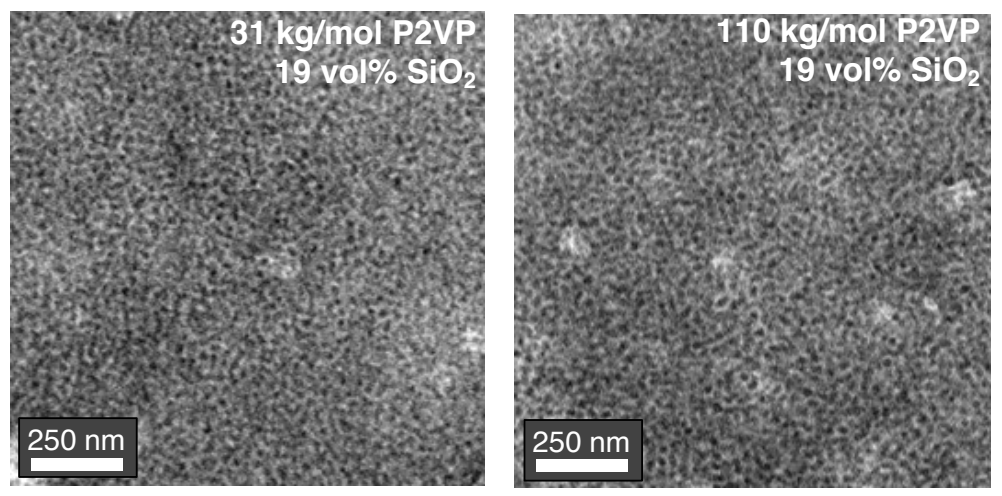

Figure S1: Transmission electron micrographs showing homogeneous dispersion of $\mathrm{SiO}_{2}$ nanoparticles in (a) $31 \mathrm{~kg} / \mathrm{mol}$ and (b) $110 \mathrm{~kg} / \mathrm{mol} \mathrm{dP2VP}$ at $19 \mathrm{vol} \%$, the highest concentration studied. The TEM specimens were prepared from $\sim 150 \mathrm{~nm}$ thick $\mathrm{P} 2 \mathrm{VP} / \mathrm{SiO}_{2}$ on $\sim 30 \mathrm{~nm}$ PS that floated from a silicon wafer in DI water and transferred to a TEM grid. Due to the high NP concentration and sample thickness ( 180 nm total), there is extensive overlap of the NPs and attenuation in the TEM image. However, $\mathrm{P} 2 \mathrm{VP} / \mathrm{SiO}_{2}$ is known to form stable dispersions. ${ }^{1-3}$ TEM images showing $\mathrm{SiO}_{2}$ dispersion in various $\mathrm{M}_{\mathrm{w}} \mathrm{P} 2 \mathrm{VP}(28-300 \mathrm{~kg} / \mathrm{mol}$ P2VP and 10 vol\%) after the same sample preparation can be found in Ref 3 . 


\section{$\underline{\text { II. RBS measurements of unannealed bilayers }}$}

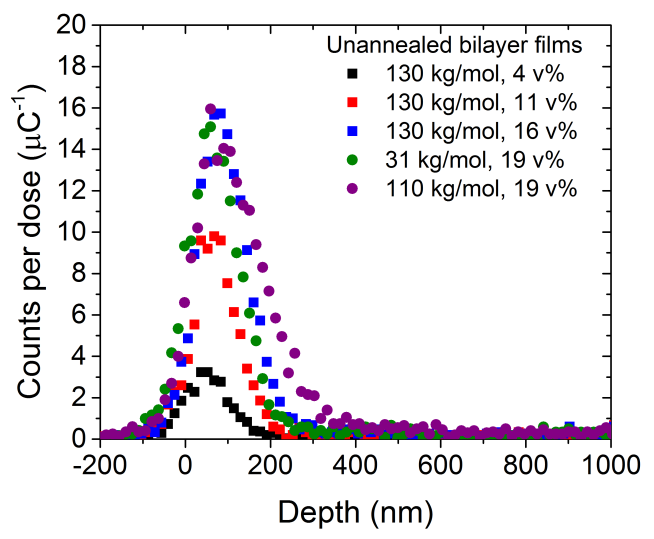

(a)

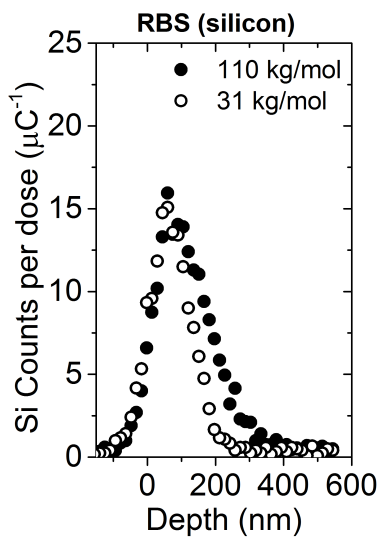

(b)

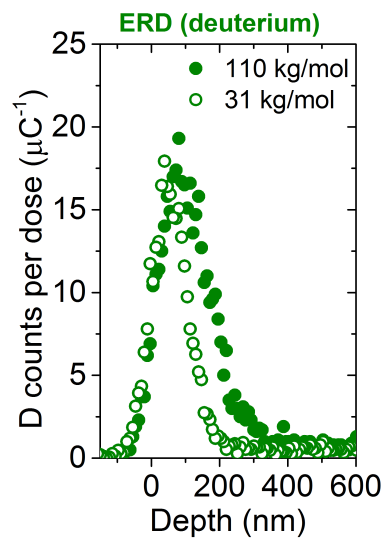

(c)

Figure S2: (a) RBS measurements of all unannealed diffusion couples showing counts in Si peak as a function of depth. (b,c) Comparison of 31 and $110 \mathrm{~kg} / \mathrm{mol}$ PNCs with RBS (b) and ERD (a). We note that the $31 \mathrm{~kg} / \mathrm{mol}$ sample (open symbols, $\sim 130 \mathrm{~nm}$ ) is thinner than the $110 \mathrm{~kg} / \mathrm{mol} \mathrm{sample} \mathrm{(closed} \mathrm{symbols,}$ $\sim 160 \mathrm{~nm}$ ), but the NP concentration is the same (Table S1). We also note that the ratio of counts in ERD and RBS (which is directly related to the relative amount of polymer and NP) are in good agreement for both samples.

Table S1: Quantitative comparison of unannealed tracer films from Figure S2a, which are defined by $\mathrm{dP} 2 \mathrm{VP} \mathrm{M}_{\mathrm{w}}$ and $\phi_{\mathrm{NP}}$. The total Si signal from RBS normalized by the dose $\left(\mathrm{I}_{\mathrm{Si}}\right)$ is calculated from Figure S2a for $-200 \mathrm{~nm}<\mathrm{z}<400 \mathrm{~nm}$. The film thickness (h) and $\phi_{\mathrm{NP}}$ were determined from fitting raw experimental data in SIMNRA. Between the different samples, the experimental $\mathrm{I}_{\mathrm{Si}}$ should depend primarily on $\phi_{\mathrm{NP}}$ and $\mathrm{h}$, and as expected, $\mathrm{I}_{\mathrm{S}} /\left(\mathrm{h} * \phi_{\mathrm{NP}}\right)$ is constant (within $\sim 10 \%$ ) for all samples. This verifies that our assignment of $h$ and $\phi_{\mathrm{NP}}$ are reasonable.

\begin{tabular}{|c|c|c|c|c|}
\hline $\begin{array}{c}\mathrm{dP} 2 \text { VP } \mathrm{M}_{\mathrm{w}} \\
(\mathrm{kg} / \mathrm{mol})\end{array}$ & $\begin{array}{c}\phi_{\mathrm{NP}} \\
(\mathrm{vol} \%)\end{array}$ & $\begin{array}{c}\mathrm{I}_{\mathrm{Si}}, \text { Integrated RBS counts per dose } \\
(-200 \mathrm{~nm}<\mathrm{z}<400 \mathrm{~nm})\end{array}$ & $\begin{array}{c}\mathrm{h}, \text { film } \\
\text { thickness }(\mathrm{nm})\end{array}$ & $\begin{array}{c}\mathrm{I}_{\mathrm{Si}} /\left(\mathrm{h}^{*} \phi_{\mathrm{NP}}\right) \\
(\text { counts/nm) }\end{array}$ \\
\hline \multirow{2}{*}{130} & 4 & 29.3 & 105 & 0.0699 \\
\cline { 2 - 5 } & 11 & 87.5 & 125 & 0.0637 \\
\cline { 2 - 5 } & 16 & 155.8 & 150 & 0.0649 \\
\hline 31 & 19 & 194.9 & 130 & 0.0641 \\
\hline 110 & 19 & 154.0 & & 0.0624 \\
\hline
\end{tabular}




\section{Bound layer thickness analysis for 31 and $110 \mathrm{~kg} / \mathrm{mol} \mathrm{dP2VP} \mathrm{PNCs}$}
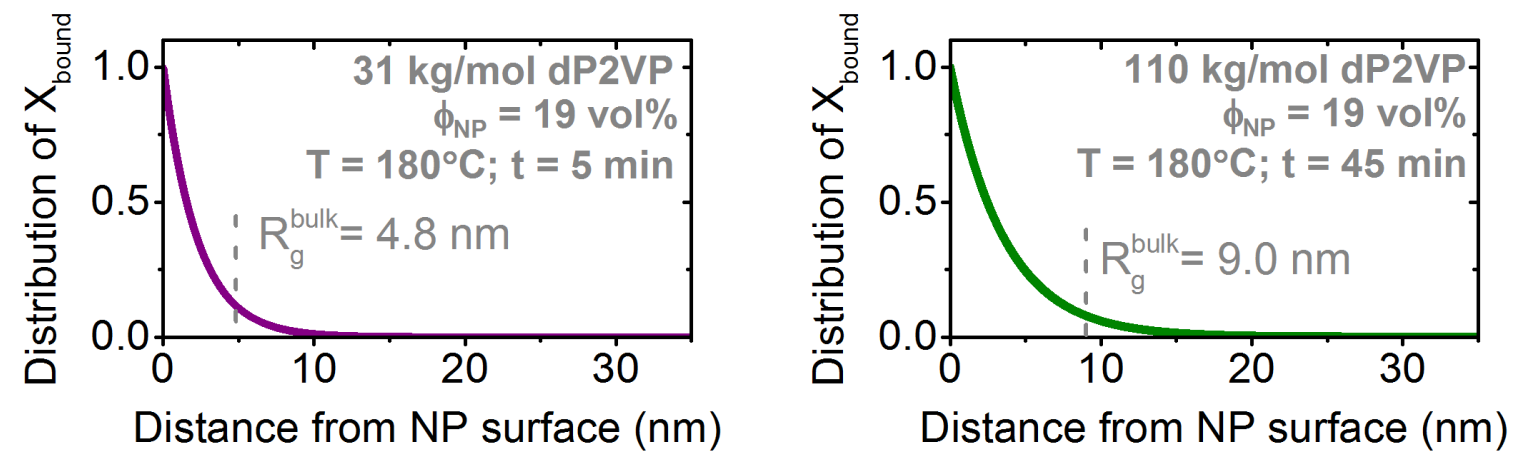

Figure S3: Analysis of bound layer thickness for $31 \mathrm{~kg} / \mathrm{mol} \mathrm{dP} 2 \mathrm{VP}$ (left) and $110 \mathrm{~kg} / \mathrm{mol} \mathrm{dP2VP}$ (right) PNCs comprised of $19 \mathrm{vol} \% \mathrm{SiO}_{2}$ and annealed for short times (5 min and 45 min respectively). In both cases, the bound layer thickness extends $\sim R_{g}$ from the NP surface, in qualitative agreement with Figure $4 \mathrm{~d}$ of the manuscript. The underlying P2VP matrix in both cases is $250 \mathrm{~kg} / \mathrm{mol}$. 


\section{$\underline{\text { IV. Measurements of bulk diffusion }}$}

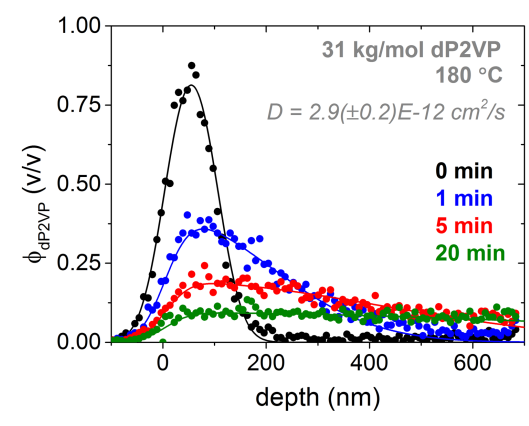

(a)

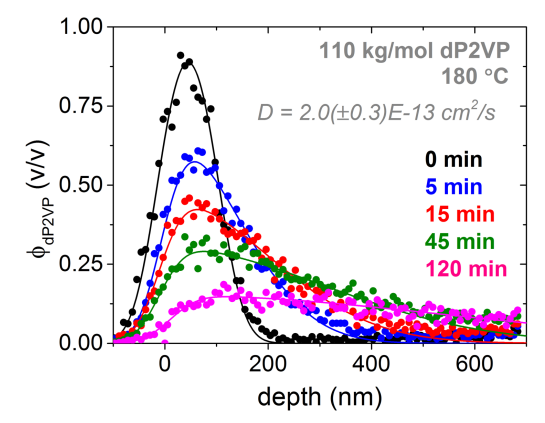

(b)

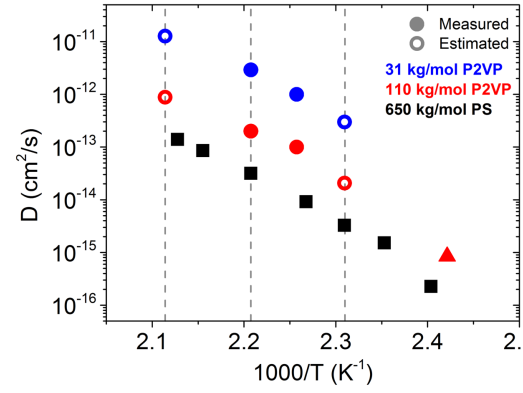

(c)

Figure S4: Measured ERD depth profiles and diffusion coefficients for (a) $31 \mathrm{~kg} / \mathrm{mol}$ and (b) $110 \mathrm{~kg} / \mathrm{mol}$ $\mathrm{dP} 2 \mathrm{VP}$ at $180^{\circ} \mathrm{C}$ and varying annealing times. (c) Bulk diffusion coefficients as a function of inverse temperature. Measurements at $160^{\circ} \mathrm{C}$ and $200^{\circ} \mathrm{C}$ were extrapolated from measurements at lower temperatures (solid circles and triangles) assuming a similar fragility as bulk PS (solid black squares). Importantly, the fragility index of chain-scale dynamics for PS and P2VP are largely independent of molecular weight and have similar values $(\sim 90) .{ }^{4}$ By comparing available $\mathrm{D}_{\text {chain }}$ measurements from PS (Ref 5) and P2VP (this work and Ref 6) in (c), this assumption seems reasonable. We also note that $\mathrm{D}_{31 \mathrm{k}} / \mathrm{D}_{110 \mathrm{k}} \sim\left(\mathrm{N}_{31 \mathrm{k}} / \mathrm{N}_{110 \mathrm{k}}\right)^{-2.1}$, in reasonable agreement with the expected $\mathrm{D} \sim \mathrm{N}^{-2.3} .7$

Table S2: Reptation times $\left(\tau_{\text {rep }}\right)$ defined as the square of the chain radius of gyration $\left(R_{\mathrm{g}}\right)$ divided by the chain diffusion coefficient (D) and considered the time required for a chain to diffuse one characteristic length in the bulk. The chain diffusion coefficient (D) is obtained from Figure S4c. These values are used to normalize for chain mobility in Figure 7 of the manuscript.

\begin{tabular}{|c|c|c|c|}
\hline \multirow{2}{*}{$\begin{array}{c}\mathrm{dP} 2 \mathrm{VP} \mathrm{M}_{\mathrm{w}} \\
(\mathrm{kg} / \mathrm{mol})\end{array}$} & \multicolumn{3}{|c|}{$\tau_{\text {rep }}=R_{g}^{2} / D_{\text {chain }}(\mathrm{s})$} \\
\cline { 2 - 4 } & $160^{\circ} \mathrm{C}$ & $180^{\circ} \mathrm{C}$ & $200^{\circ} \mathrm{C}$ \\
\hline 31 & 0.78 & 0.08 & 0.02 \\
\hline 110 & 39 & 4.1 & 0.92 \\
\hline
\end{tabular}




\section{$\underline{V}$. Efficacy of restricting NP diffusion by increasing matrix $M_{w}$}

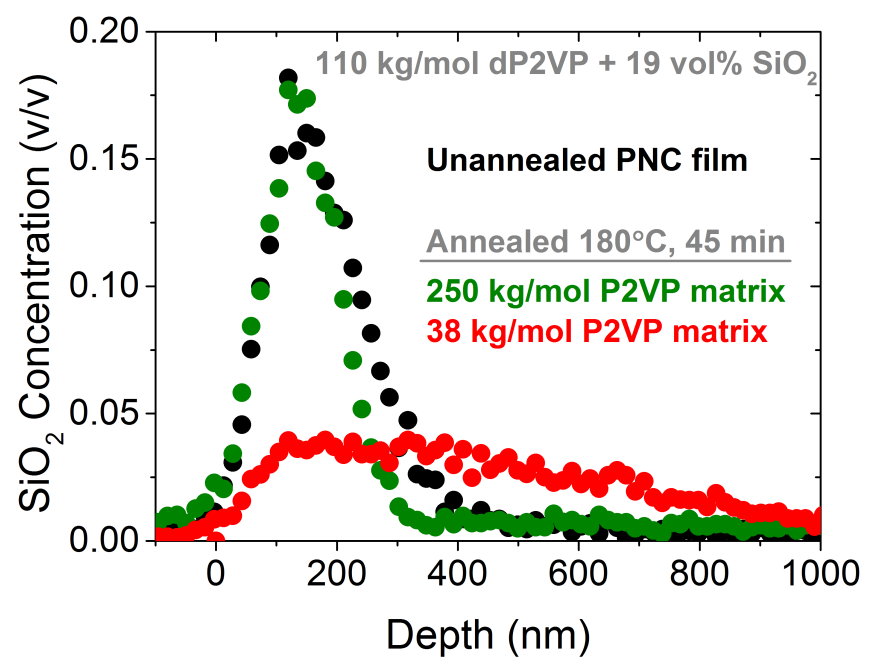

Figure S5: Effect of matrix molecular weight on NP diffusion. NPs freely diffuse into $38 \mathrm{~kg} / \mathrm{mol} \mathrm{P2VP}$ and NPs remain in the top film when the bottom film is $250 \mathrm{~kg} / \mathrm{mol}$. The extracted diffusion coefficient from NPs into $38 \mathrm{~kg} / \mathrm{mol}$ is in good agreement with Ref 3, suggesting that NPs are diffusing as individual entities in our PNCs samples, even for tracer PNC films with $\phi_{\mathrm{NP}}=19 \mathrm{vol} \%$. 


\section{References:}

(1) Jouault, N.; Moll, J. F.; Meng, D.; Windsor, K.; Ramcharan, S.; Kearney, C.; Kumar, S. K. Bound Polymer Layer in Nanocomposites. ACS Macro Lett. 2013, 2 (5), 371-374.

(2) Holt, A. P.; Griffin, P. J.; Bocharova, V.; Agapov, A. L.; Imel, A. E.; Dadmun, M. D.; Sangoro, J. R.; Sokolov, A. P. Dynamics at the Polymer/Nanoparticle Interface in Poly(2-Vinylpyridine)/ Silica Nanocomposites. Macromolecules 2014, 47 (5), 1837-1843.

(3) Griffin, P. J.; Bocharova, V.; Middleton, L. R.; Composto, R. J.; Clarke, N.; Schweizer, K. S.; Winey, K. I. Influence of the Bound Polymer Layer on Nanoparticle Diffusion in Polymer Melts. ACS Macro Lett. 2016, 5 (10), 1141-1145.

(4) Agapov, A. L.; Novikov, V. N.; Hong, T.; Fan, F.; Sokolov, A. P. Surprising Temperature Scaling of Viscoelastic Properties in Polymers. Macromolecules 2018, 51 (13), 4874-4881.

(5) Tung, W.-S.; Griffin, P. J.; Meth, J. S.; Clarke, N.; Composto, R. J.; Winey, K. I. TemperatureDependent Suppression of Polymer Diffusion in Polymer Nanocomposites. ACS Macro Lett. 2016, 735-739.

(6) Bailey, E. J.; Griffin, P. J.; Composto, R. J.; Winey, K. I. Multiscale Dynamics of Small, Attractive Nanoparticles and Entangled Polymers in Polymer Nanocomposites. Macromolecules 2019, 52 (5), 2181-2188.

(7) Lodge, T. Reconciliation of the Molecular Weight Dependence of Diffusion and Viscosity in Entangled Polymers. Phys. Rev. Lett. 1999, 83 (16), 3218-3221. 